\title{
CONTEXTO, CONTEÚDO E PROCESSO DA MUDANÇA ESTRATÉGICA EM UMA ENTIDADE DE CLASSE DA INDÚSTRIA BRASILEIRA
}

\author{
CONTEXT, CONTENT AND PROCESS OF THE STRATEGIC CHANGE IN AN ASSOCIATION OF BRAZILIAN \\ INDUSTRIES
}

\author{
CONTEXTO, CONTENIDO Y PROCESO DEL CAMBIO ESTRATÉGICO EN UNA ENTIDAD DE CLASE DE LA \\ INDUSTRIA BRASILEÑA
}

\author{
KARINA COSTA LIMA MENDES CAVALEIRO \\ Mestre \\ Sistema FIEC - Brasil \\ karinacavaleiro@gmail.com \\ JOSÉ DE PAULA BARROS NETO \\ Doutor \\ Universidade Federal do Ceará - Brasil \\ barrosneto@gercon.ufc.br \\ Submetido em: 22/12/2015 \\ Aprovado em: 19/07/2016
}

Doi: alcance. v23n3. p372-390

\begin{abstract}
RESUMO
O presente artigo tem como objetivo analisar a mudança estratégica realizada por uma federação das indústrias brasileira, utilizando como abordagem teórica as dimensões de contexto, conteúdo e processo, sugeridas por Pettigrew (2013) para o estudo sobre o tema nas organizações. A pesquisa, caracterizada como um estudo de caso qualitativo, utilizou como evidência entrevistas, documentos e arquivos de uso público, a fim de responder à questão norteadora: como ocorreu a mudança estratégica no Sistema FIEC, no período de 2009 a 2014, em termos de contexto, conteúdo e processo? Como resultado, foi possível identificar um contexto externo marcado por baixos níveis de investimento, inovação e produtividade e um contexto interno pela revisão do planejamento estratégico. Como conteúdo da mudança, projetos de tecnologia da informação, marketing e custos. Quanto ao processo, observou-se que, a partir da avaliação do ambiente pelas lideranças estratégicas, foram desenvolvidos projetos, que, apesar de iniciarem em períodos distintos, faziam parte de uma mesma estratégia que visava à ruptura de uma cultura de passividade, buscando uma inteligência organizacional que passava pela integração da atuação das organizações.
\end{abstract}

Palavras-chave: Mudança organizacional. Estratégia. Federação das indústrias.

\section{ABSTRACT}

This article analyzes the strategic change made by a federation of Brazilian industries, using as a theoretical approach the context of dimensions, content and process suggested by Pettigrew (2013) for the study of the subject in organizations. The research, characterized as a qualitative case study, used as evidence, interviews, documents and publicly available files, in order to answer the main question: how were the strategic changes carried out in the FIEC system, from 2009 to 2014, in terms of their context, content and process? As a result, it was possible to identify an external environment characterized by low levels of investment, innovation and productivity, and an internal context for the review of strategic planning. The content of the changes included information technology projects, marketing and costs. In terms of process, projects were observed, in the environmental assessment carried out by the strategic leaderships, that despite starting at different times, were developed as part of the same 
strategy that attempted to break with the culture of passivity, seeking an organizational intelligence that would form part of the work of the organizations.

Keywords: Organizational change. Strategy. Industry federation.

\section{RESUMEN}

El presente artículo tiene como objetivo analizar el cambio estratégico realizado por una federación brasileña de las industrias, utilizando como abordaje teórico las dimensiones de contexto, contenido y proceso sugeridas por Pettigrew (2013) para el estudio acerca del tema en las organizaciones. La investigación, caracterizada como un estudio de caso cualitativo, utilizó como evidencia entrevistas, documentos y archivos de uso público, a fin de responder a la cuestión orientadora: ¿cómo ocurrió el cambio estratégico en el Sistema FIEC durante el período de 2009 a 2014 en términos de contexto, contenido y proceso? Como resultado fue posible identificar un contexto externo marcado por bajos niveles de inversión, innovación y productividad, y un contexto interno señalado por la revisión del planeamiento estratégico. Como contenido del cambio, proyectos de tecnología de la información, marketing y costos. En relación al proceso, se observó que a partir de la valoración del ambiente por los liderazgos estratégicos se desarrollaron proyectos que, a pesar de haber sido iniciados en períodos distintos, formaban parte de una misma estrategia cuyo propósito era la ruptura de una cultura de pasividad, buscando una inteligencia organizacional que pasaba por la integración de la actuación de las organizaciones.

Palabras clave: Cambio organizacional. Estrategia. Federación de las industrias.

\section{INTRODUÇÃO}

A dinâmica do ambiente de atuação das organizações, marcada por fatores conjunturais, exige das organizações a capacidade de perceber e se ajustar à velocidade das mudanças, podendo tal capacidade ser traduzida como o próprio desafio da sua sustentabilidade. No entendimento de Motta (2007), a mundialização da economia e a rapidez das alterações no contexto social e político afetam igualmente a sobrevivência imediata e a viabilidade futura das organizações. No contexto organizacional, a mudança exige intenção, cooperação e apoio. Assim, ao iniciar a mudança, a organização deve traçar um modelo de forma que ideias, pessoas e realidade se encontrem em um todo harmônico e produzam novos resultados.

Dentre os modelos de mudança organizacional estudados, o presente trabalho foca a pesquisa, como delimitação do tema, no modelo da intenção estratégica, apresentado por Motta (2007), buscando alinhamento ao trabalho de autores como Pettigrew (2013), que defende que as organizações, embora sob forte pressão ambiental, possuem condições de fazer escolhas quanto às suas ações e estratégias, mesmo que elas sejam limitadas de alguma forma pelo contexto. Tais abordagens colocam a mudança estratégica como fator-chave de sobrevivência e crescimento das organizações, configurando-se, então, a relevância de um fenômeno a ser estudado no contexto da análise dos processos organizacionais.

Corroborando com esse entendimento, verificou-se que no contexto da gestão organizacional o termo estratégia, associado à mudança organizacional, tem sido destacado nos estudos desenvolvidos acerca do tema. Diversos autores, ao discutirem abordagens sobre a mudança, fazem-nas sob o cunho da estratégia, a exemplo de: Palácios (2014), Saeed e Wang (2013), Coraiola et al. (2012), Gohr (2011), Borges (2009), Brunninge et al. (2007), Fiss e Zajac (2006), Suarez e Oliva (2005), Amis et al. (2004), Silva e Vergara (2003), Graetz (2000) e Gioia e Chittipeddi (1991).

0 presente estudo diferencia-se dos demais por propor o estudo da mudança estratégica em uma entidade de classe da indústria brasileira, organização associativa e de serviço social, tomando como base para o desenvolvimento da pesquisa a abordagem de Pettigrew (2013), na qual toma o contextualismo como teoria para a pesquisa da mudança organizacional. Nela, a tarefa é identificar a mistura de causas da mudança, considerando que a formação da estratégia nas organizações é um processo contínuo, consistindo a estratégia nas escolhas feitas e postas em prática em processos, envolvendo indivíduos e grupos, e que se desenvolvem dentro de um padrão de pensar sobre o mundo, avaliar esse mundo e agir sobre esse mundo (PETTIGREW, 1990). 
Considerando que grande parte das pesquisas observadas sobre os processos de mudança enfoca as organizações privadas ou públicas, a análise da mudança estratégica em uma entidade de classe revela peculiaridades que não são comumente abordadas na literatura da área. Entre outros fatores, a forte vinculação das estratégias da organização com fatores socioeconômicos representa uma variável crítica para estudos de mudança organizacional, em especial, à abordagem contextualista de Pettigrew, que propõe uma análise holística e dinâmica do processo de mudança estratégica, o que ressalta a relevância desta pesquisa.

Pretende, então, o presente trabalho somar-se ao conjunto de reflexões relacionado ao fenômeno da mudança organizacional, buscando identificar a variedade e a mistura de causas da mudança e explorar algumas das condições e dos contextos em que ocorrem essas misturas (PETTIGREW, 1990), com a proposição de um estudo acerca da mudança estratégica, tomando como referência o Sistema Federação das Indústrias do Estado do Ceará (Sistema FIEC). A organização em questão trata-se de um organismo formado por um conjunto de instituições: Federação das Indústrias do Estado do Ceará (FIEC), Serviço Nacional de Aprendizagem Nacional (SENAI/CE), o Serviço Social da Indústria (SESI/CE), o Instituto Euvaldo Lodi (IEL/CE), que integradas à Confederação Nacional das Indústrias $(\mathrm{CNI})$, formam o Sistema Indústria, uma rede nacional de caráter privado responsável por iniciativas de apoio ao setor industrial brasileiro, oferecendo serviços de educação, formação profissional, capacitação empresarial, segurança, saúde e soluções técnicas e de inovação às indústrias (CNI, 2014).

Desse modo, constitui-se como unidade de análise do presente estudo a mudança estratégica organizacional, figurada por meio dos projetos de mudança de estratégia implantados pelo Sistema FIEC, que tiveram sua implantação entre 2009 e 2014. Surge, então, a formulação do problema que norteia a presente pesquisa: como ocorreu a mudança estratégica no Sistema FIEC, no período de 2009 a 2014, em termos de contexto, conteúdo e processo? Com o intuito de responder à questão de pesquisa, foi traçado o objetivo de analisar a mudança estratégica no Sistema FIEC, no período de 2009 a 2014, em termos de contexto, conteúdo e processo. $E$, ainda, os objetivos específicos: 1) identificar o contexto interno e externo da organização envolvendo o período de estudo, ou seja, o contexto da mudança; 2) descrever as ações de mudança estratégica que foram implantadas na organização ao longo do período de estudo, ou seja, o conteúdo da mudança; e 3) analisar os estágios da mudança estratégica no período de estudo, sob a ótica dos gestores da organização, ou seja, o processo das mudanças.

\section{MUDANÇA ESTRATÉGICA NAS ORGANIZAÇÕES}

Verificou-se na literatura uma série de estudos relacionados ao fenômeno da mudança organizacional e seus desdobramentos no contexto das organizações, que vão além dos autores clássicos ao tema, encontrandose também em diversos estudos acadêmicos que ilustram distintas questões acerca do tema.

Segundo Comin e Sausen (2016), os ambientes organizacionais caracterizam-se por constantes mudanças, que exigem uma rápida adaptação em relação às mudanças que ocorrem no mercado e na capacidade de inovação da empresa, proporcionando uma melhoria contínua e diferenciada das suas atividades, tornando-a competitiva e capaz de tomar decisões eficientes e eficazes. Para os referidos autores, o processo de mudança nas organizações é influenciado pelo determinismo, assim como pelas escolhas organizacionais.

No tocante à teoria da mudança organizacional, Motta (2007) considera que a tentativa de manter a mudança sob controle levou à pluralidade de propostas sobre a melhor maneira de abordá-la e conduzi-la, destacando, então, três categorias dos modelos de mudança organizacional: intenção estratégica, reação adaptativa e aprendizado contínuo. 0 modelo da intenção estratégica considera que a organização pode adaptarse ao seu ambiente por meio de reestruturação planejada e direcionada pela alta gerência; o modelo da reação adaptativa considera a mudança como uma resposta planejada a uma situação problemática; e, por fim, o modelo do aprendizado contínuo, considerando o processo de mudança amplo, aberto e experimental, tratando igualmente problemas e soluções de forma menos imediatista (MOTTA, 2007).

Ainda, Mintzberg, Ahlstrand e Lampel (2007) sugerem três métodos básicos para o processo de mudança: mudança planejada, que exige um conjunto de procedimentos a ser seguido; mudança conduzida, guiada por uma pessoa ou grupo em posição de autoridade que assegura que a mudança aconteça; e mudança desenvolvida, que de alguma forma acontece ou é guiada por pessoas que não ocupam posições de autoridade.

Em adição, para Wood Jr. et al. (1994, p. 64), a mudança organizacional configura-se como "qualquer transformação de natureza estrutural, estratégica, cultural, tecnológica, humana ou de qualquer outro componente,

Revista Alcance - Eletrônica - vol. 23 - n. 3 - jul./set. 2016 
capaz de gerar impacto em partes ou no conjunto da organização". Para os autores, as organizações devem interpretar continuamente o ambiente, originando movimentos internos de mudança. Desse modo, o ponto-chave é a passagem de uma postura passiva ou reativa para uma postura proativa, implicando a constante manipulação, por parte dos líderes, de símbolos, valores e linguagem, sendo substituído, por fim, o controle coercitivo pelo controle via cultura organizacional.

Por sua vez, Robbins (2005) destaca seis forças para a mudança organizacional: a natureza mutável da força de trabalho, a tecnologia, os choques econômicos, a competição, as tendências sociais e a política internacional. Nesse sentido, quando a concorrência lança novos produtos, quando o governo baixa novas leis, quando importantes fontes de insumo saem do mercado ou quando qualquer outra mudança ambiental acontece, a organização precisa adaptar-se. A mudança, nessa visão, refere-se a fazer as coisas de maneira diferente, sendo necessário uma mudança planejada, entendida como uma atividade intencional e orientada para resultados, com o objetivo de melhorar a capacidade da organização de se adaptar às mudanças em seu ambiente e mudar o comportamento dos colaboradores.

Verificou-se, mais especificamente, que, sob o cunho da estratégia, a discussão sobre a mudança organizacional amplia-se por considerar, além das dimensões políticas e culturais do fenômeno, a cognição e as relações dos envolvidos no processo ao longo do tempo de forma holística. A exemplo, Mintzberg, Lampel, Quinn e Ghoshal (2007) observaram uma ligação tão estreita entre estratégia e mudança, a ponto de afirmarem que administrar estratégia é administrar mudança, enfatizando ainda que estratégia consiste em mudança e não em continuidade. A mudança estratégica, então, é entendida como uma necessidade de reorientação, significando sair de um domínio familiar para um futuro não tão bem definido, em que muitas das velhas regras não se aplicam mais, sendo necessário que se abandonem as raízes de sucessos passados e se desenvolvam novas habilidades e atitudes, configurando-se tal exigência no desafio mais difícil enfrentado por um gerente.

Ademais, Porter (2004) destaca como essência da formulação da estratégia a sua relação com 0 ambiente. Embora o ambiente relevante seja muito amplo, abrangendo tanto forças sociais como econômicas, 0 aspecto principal do ambiente é a indústria ou as indústrias em que a organização compete. Dessa forma, a estrutura industrial tem forte influência na determinação das estratégias potencialmente disponíveis; configurandose como ponto básico para a organização as suas habilidades internas em lidar com as forças externas dessa estrutura. Bethlem (2002) coloca os objetivos organizacionais com ponto de partida para a determinação da estratégia, acrescentando que a utilização de estratégias é uma atividade de conteúdo e de processo, em que a aprendizagem dos conceitos e das técnicas pelos membros da organização, a aceitação e a implantação pelos participantes das ações necessárias são os fatores decisivos para o sucesso ou não de uma estratégia.

Com relação ao processo de implantação, Ansoff (1990) afirma que as mudanças estratégicas frequentemente são introduzidas sem levar em conta a resistência por elas produzida. Assim, a mudança é planejada, explicada aos que são responsáveis por sua implantação e lançada. Porém, quando surgem ineficiências na implantação, elas são tratadas no nível do processo de mudança e não no nível das raízes e fontes da resistência, sendo utilizado o poder para superar deficiências. Embora seja ineficiente, tal tipo de comportamento eventualmente produz resultados, desde que os proponentes da mudança tenham o potencial poder necessário. Contudo, esse enfoque era satisfatório quando as descontinuidades estratégicas eram raras e o ritmo de mudança era lento; à medida que o ambiente se torna mais turbulento, os administradores são forçados a gerir a mudança de maneira mais rápida e eficaz (ANSOFF, 1990).

Para Johnson, Scholes e Whittington (2008), quando se trata de mudança estratégica, há ênfase nas pessoas que estão no topo da organização, sendo, entretanto, importante pensar na agência da mudança de forma mais ampla. Um agente de mudança é uma pessoa ou um grupo que ajuda a efetivar a mudança estratégica na organização, assim, o criador de uma estratégia pode ou não ser o agente de mudança, podendo, ainda, precisar usar outras pessoas para liderar as mudanças estratégicas, quer sejam consultores ou gerentes.

Ampliando a discussão, Ferreira e Camargo-Borges (2016) defendem que, com toda a revolução tecnológica, cultural, social e política, entra-se em um novo paradigma de um mundo conectado, globalizado e com novos desafios a serem enfrentados. Teorias e clássicos métodos de intervenção e mudança parecem não ser suficientes neste novo contexto. Para os autores, especificamente, o campo organizacional passa por momentos de crise e de mudanças, tornando-se necessário ressignificar o papel das empresas, o papel dos líderes, o papel dos processos burocráticos e o papel dos valores.

Em suma, conforme observado por Gohr (2011), apesar das diferentes visões, existe uma linha de concordância de que as organizações se transformam ou precisam transformar-se continuamente, observando-se 
que essas são sistemas adaptativos complexos que continuamente se ajustam ao contexto em que estão inseridas, de forma que esse ajuste pode resultar em mudanças estratégicas que, consequentemente, podem levar a organização a uma transformação organizacional.

Nesse contexto, destaca-se o modelo de análise de mudança estratégica de Pettigrew (1977, 1987, 2013), que acabou por servir de base conceitual e metodológica para o presente trabalho de pesquisa. Os trabalhos de Pettigrew, desde a década de 1970 até os dias atuais, têm se constituído como referência na literatura a esse respeito. $O$ autor apresenta um modelo de estudo da mudança estratégica nas organizações que envolve a interação entre o contexto, o processo e o conteúdo da mudança, junto com a habilidade de regular as relações entre os três elementos, numa perspectiva contextualista.

$\mathrm{Na}$ teoria contextualista os pontos-chave a enfatizar na análise da mudança são: em primeiro lugar, a importância de estudar a mudança no contexto de níveis interligados de análise; em segundo lugar, a importância da relação temporal da mudança, localizando-a no passado, presente e futuro; em terceiro lugar, a necessidade de explorar contexto, ação e o nexo de causalidade. Nesse tipo de análise a causa da mudança não é linear nem singular - a busca de uma grande teoria simples e singular de mudança é improvável dar frutos. Na teoria e prática da mudança, a tarefa é identificar a variedade e a mistura de causas da mudança e explorar ao longo do tempo algumas das condições e dos contextos em que ocorrem essas misturas (PETTIGREW, 1990).

Em adição, Pettigrew (1977) parte da compreensão de que a formação da estratégia nas organizações é um processo contínuo, consistindo a estratégia nas escolhas feitas e postas em prática em processos envolvendo indivíduos e grupos, em vários níveis organizacionais, e que se desenvolvem dentro de um padrão de pensar sobre o mundo, avaliar esse mundo e agir sobre esse mundo.

Do ponto de vista operacional, Pettigrew $(1987,2013)$ propõe três conceitos de base, que devem ser considerados de maneira interligada: o contexto, o conteúdo e o processo. 0 contexto da mudança, que se distingue em contexto externo e interno, refere-se tanto ao ambiente social, econômico, político e competitivo em que a empresa atua, quanto ao conjunto de fatores que influenciam a formação das estratégias dentro da organização, como a cultura organizacional, o contexto político da organização e as relações de poder. 0 conteúdo da mudança faz referência às áreas específicas de mudança que estão sendo examinadas. Já o processo de mudança refere-se às ações, às reações e às interações das partes interessadas (PETTIGREW, 1987, 2013).

A partir da concepção das dimensões essenciais aos processos de mudança estratégica, o referido autor propõe para a análise da mudança quatro estágios: 1) desenvolvimento, envolvendo questões de percepção de problemas ambientais que requerem mudanças; 2) reconhecimento e compreensão dos problemas, envolvendo questões acerca da construção das mudanças; 3) planejamento e execução, envolvendo questões de planejamento e condução das ações; e 4) estabilidade da mudança, envolvendo questões acerca da garantia da continuidade da mudança, como recompensas e padrões de poder que sustentem a nova posição. Relacionados, ainda, aos referidos estágios da análise da mudança, são identificados cinco problemas-chave para a gerência da mudança estratégica, que acabam por se constituir nas áreas-problema a serem examinadas nas organizações em processo de mudança estratégica: a) avaliação do ambiente; b) liderança da mudança; c) ligação entre mudança estratégica e operacional; d) tratamento dos recursos humanos como bens ativos e como responsabilidades da organização; e e) desenvolvimento de uma abordagem coerente (HICKSON, PUGH, 2004).

Por fim, Pettigrew (2013) observou que o padrão de mudança observado nas organizações consistiu numa mistura complexa de ajustes no núcleo de crenças dos principais tomadores de decisão, seguido por mudanças na estrutura, que reforçavam as mudanças nas crenças que, por sua vez, destas mudanças nas crenças e estrutura começou a emergir a nova estratégia. Nessa visão, a cultura organizacional, considerada no seu nível mais profundo como um conjunto complexo de valores, crenças e pressupostos dos principais tomadores de decisão, configura-se como mecanismo chave para promover as mudanças estratégicas organizacionais.

Afinado com esse entendimento, o presente trabalho adotará a referida abordagem contextualista, uma vez que para a análise do processo de mudança estratégica do Sistema FIEC se baseará na análise processual e contextual dos fenômenos, identificando as ações e as reações das mudanças estratégicas ocorridas.

\section{METODOLOGIA}

Considerando o objetivo de estudar como ocorreu a mudança estratégica no Sistema FIEC, trata-se de uma pesquisa interpretativa de cunho qualitativo, quanto à natureza dos dados e à abordagem do problema, uma vez que não emprega um instrumental estatístico como base do processo de análise, mas adota uma metodologia

Revista Alcance - Eletrônica - vol. 23 - n. 3 - jul./set. 2016 
que busca explorar a complexidade de determinado problema, vivido por grupos sociais (RICHARDSON et al., 2008). Quanto aos meios, é documental, pois faz uso de dados encontrados em diversos documentos da organização investigada; e é de campo, já que propõe a coleta de dados primários no contexto real da organização em estudo, mediante entrevistas com os gestores do nível estratégico do Sistema FIEC. No que diz respeito à estratégia de pesquisa, utilizou-se o estudo de caso único e holístico (YIN, 2010). Único, pois é análogo a um experimento único, relacionado, ainda, à especificidade do Sistema FIEC, na qual não há outra organização semelhante no estado do Ceará; e holístico, pois envolve apenas uma unidade de análise, a mudança estratégica.

Por oportuno, destaca-se que as mudanças organizacionais do presente estudo de caso foram delineadas a partir da preocupação do Sistema Indústria em atender às demandas da indústria brasileira, de forma mais sinérgica entre suas entidades integrantes, o que mobilizou esforços de planejamento que resultaram no desdobramento de processos de reformulação estratégica nacional, implantados através de projetos de mudanças estratégicas (CNI, 2008). Detalhando em uma linha do tempo, em 2004, a Confederação Nacional da Indústria (CNI), desenvolveu o mapa da indústria brasileira, documento que apontou demandas da indústria para o Sistema Indústria, dentro de seu campo de atuação. Com base em tais demandas, o Sistema Indústria realizou, em 2005, seu planejamento estratégico integrado, sendo, em 2006, desdobrado em mapas especíicos para cada instituição: SESI, SENAI e IEL. Enfim, em 2007, foram formulados projetos de mudanças estratégicas, adequados a cada regional (CNI, 2008).

Constitui-se, então, como unidade de análise do presente estudo, a mudança estratégica no Sistema FIEC (FIEC, SESI/CE, SENAI/CE E IEL/CE), figurada através da proposição de projetos que tiveram seu desenvolvimento entre 2009 e 2014.

Assim, após as definições do estudo de caso e da unidade de análise, partiu-se para a revisão da literatura e a identificação dos conceitos, nas quais, visando facilitar a coleta e a análise dos dados de forma objetiva e coerente com a questão de pesquisa, foram definidas e agrupadas as categorias de análise, que, segundo Minayo et al. (2009), se referem a um conceito que abrange elementos com características comuns ou que se relacionam entre si, empregadas para se estabelecer classificações numa tentativa de caminhar na objetivação durante a análise. Nesse entendimento, a definição das categorias tomou como base a abordagem de Pettigrew (2013) para a análise da mudança estratégica, sendo definidas categorias para cada uma das dimensões da análise proposta pelo referido autor - contexto, conteúdo e processo -, conforme apresenta o Quadro 1.

\section{Quadro 1: Conceitos das categorias de análise sob a abordagem de Pettigrew (2013)}

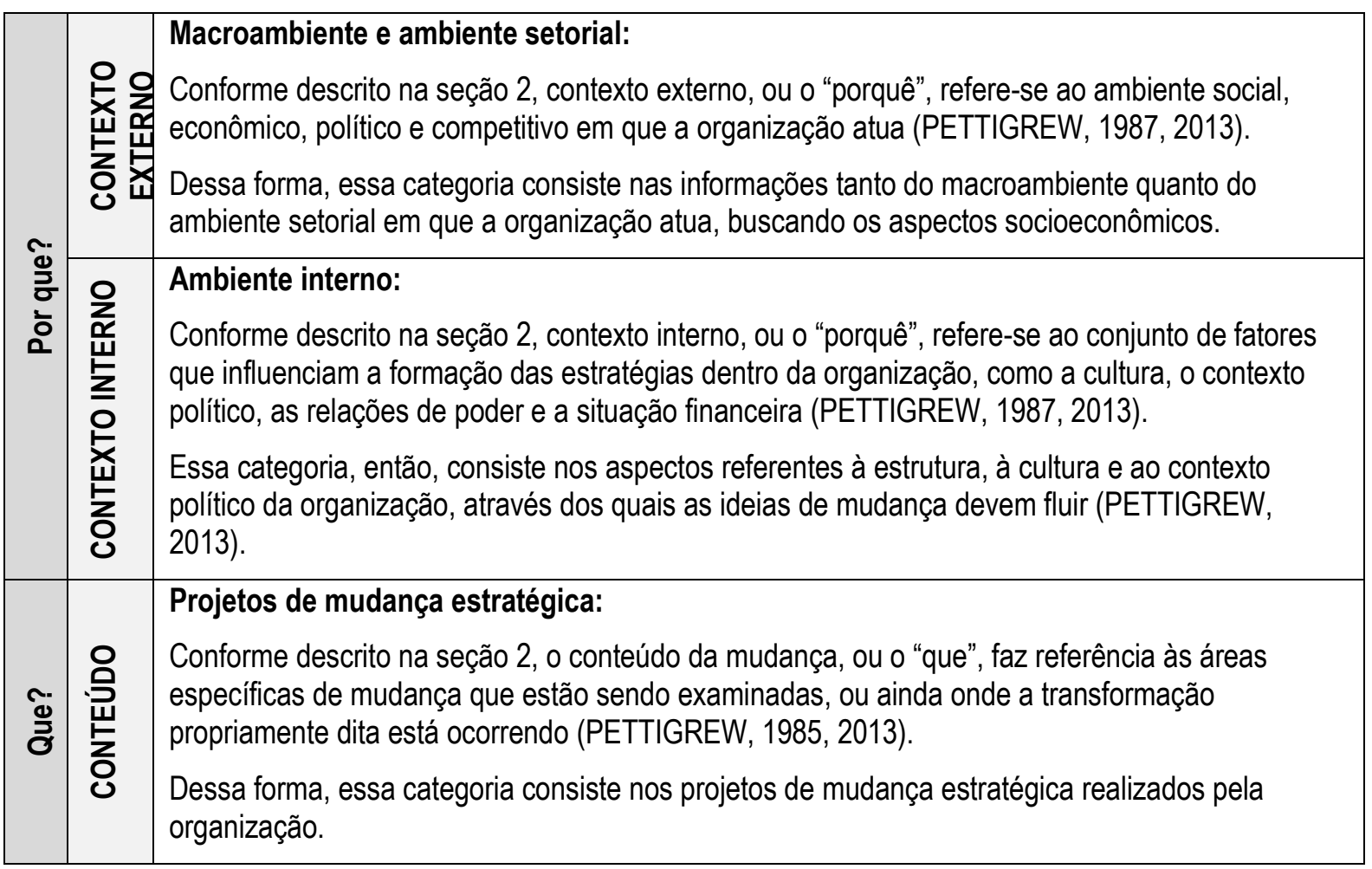




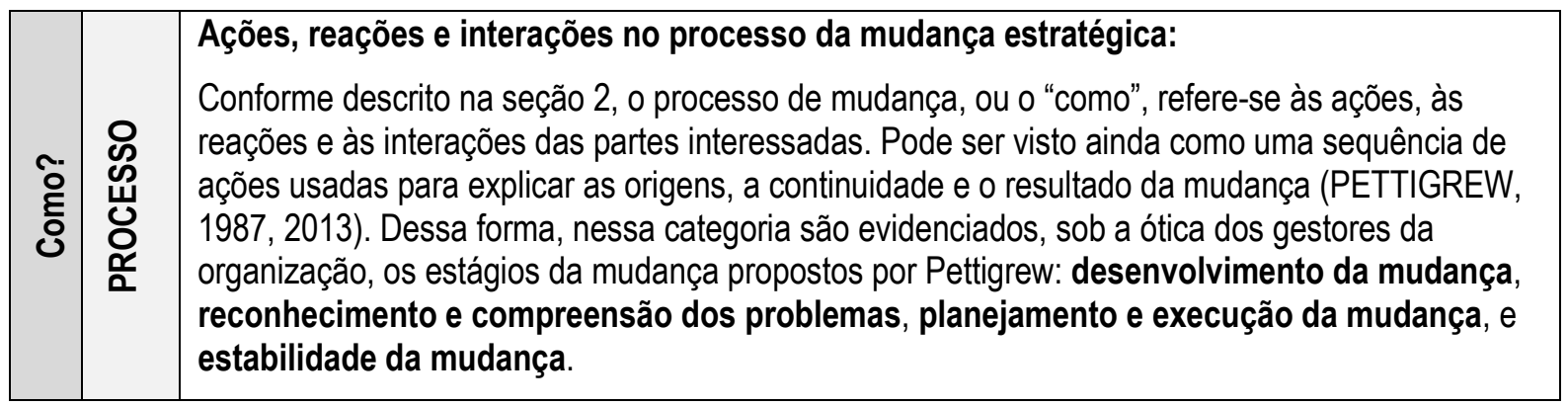

Fonte: Elaborado pela autora, adaptado de $\operatorname{Gohr}(2005,2011,2013)$.

Como fonte de evidência foram utilizadas: documentação, registros em arquivo e entrevistas. A pesquisa iniciou-se com a coleta da documentação, que objetivou tanto descrever o conteúdo da mudança, ou seja, quais foram as ações de mudança implantadas no Sistema FIEC, como identificar o seu contexto interno, sendo pesquisados documentos internos, disponibilizados pela organização ou disponíveis nos portais eletrônicos. Em seguida, foram pesquisados os registros em arquivo, documentos disponíveis nos portais de instituições, como ABDI, BCB, IPEA, IPECE, IEDI e IBGE, utilizados para identificar o contexto externo.

Por fim, foram realizadas as entrevistas, que objetivaram levantar como os gestores perceberam os estágios da mudança estratégica, tomado na presente pesquisa como o processo da mudança. Foram utilizados como critérios para a escolha dos entrevistados os gestores com perfil de atuação estratégica (presidente, superintendente, diretor regional, gerente e assessores), que vivenciaram as mudanças implantadas no período do estudo (2009 a 2014) e que se trataram dos indivíduos iniciadores e condutores da mudança, com condições de ter uma visão abrangente sobre a organização e o processo da mudança. Nesse sentido, a partir do contato com os entrevistados, via ligação telefônica e correio eletrônico, foram realizadas, pela pesquisadora, de forma presencial, dez entrevistas, de, em média, uma hora cada. Após a conclusão de cada entrevista, o material gravado foi transcrito como forma de auxiliar a análise de conteúdo.

0 trabalho de campo teve duração de dois meses, sendo realizado pela pesquisadora nos meses de junho e julho de 2015. Ressalta-se que, na quarta seção deste artigo, os gestores entrevistados são identificados pelos números de 1 a 10, sendo as citações diretas e indiretas referenciadas por essa identificação numérica.

Para a análise dos dados, definiu-se, além da análise documental para a documentação e os registros em arquivo, a análise de conteúdo para as entrevistas. 0 tratamento da documentação buscou a descrição dos projetos de mudança implantados, identificando seu período, seus objetivos e suas etapas, além da identificação da estrutura e da cultura da organização. Já o tratamento dos registros em arquivo buscou evidenciar os aspectos socioeconômicos do macroambiente e ambiente setorial de atuação da organização.

No tocante ao tratamento com o material das entrevistas, esse foi ancorado na proposta de Minayo et al. (2009) e envolveu as etapas: pré-análise, exploração do material e tratamento dos resultados. Como pré-análise, foi realizada a leitura das entrevistas, buscando a visão do todo e a apreensão das particularidades. Buscou-se, ainda, segmentar as subcategorias dos estágios de análise do processo da mudança, a fim de objetivar a construção das temáticas evidenciadas, conforme apresenta o Quadro 2. 
Quadro 2: Visão geral das categorias e subcategorias da presente pesquisa

\begin{tabular}{|c|c|c|c|c|c|}
\hline Questão & Dimensões & Categorias & \multicolumn{2}{|c|}{ Subcategorias } & Análise \\
\hline \multirow{7}{*}{$\begin{array}{l}\text { Como } \\
\text { ocorreu a } \\
\text { mudança } \\
\text { estratégica } \\
\text { no Sistema } \\
\text { FIEC, no } \\
\text { período de } \\
2009 \text { a } \\
2014, \text { em } \\
\text { termos de } \\
\text { conteúdo, } \\
\text { contexto e } \\
\text { processo? }\end{array}$} & $\begin{array}{l}\text { Contexto } \\
\text { externo }\end{array}$ & $\begin{array}{l}\text { Macroambiente e } \\
\text { ambiente setorial }\end{array}$ & \multicolumn{2}{|l|}{$\begin{array}{l}\text { Macroambiente } \\
\text { Ambiente setorial }\end{array}$} & \multirow{7}{*}{$\begin{array}{l}\text { Temáticas } \\
\text { evidenciadas } \\
\text { na pesquisa }\end{array}$} \\
\hline & $\begin{array}{l}\text { Contexto } \\
\text { interno }\end{array}$ & $\begin{array}{l}\text { Estrutura, cultura } \\
\text { e contexto político }\end{array}$ & \multicolumn{2}{|l|}{ Ambiente interno } & \\
\hline & Conteúdo & $\begin{array}{l}\text { Ações específicas } \\
\text { de mudança } \\
\text { estratégica }\end{array}$ & \multicolumn{2}{|c|}{ Projetos de mudança estratégica } & \\
\hline & \multirow{4}{*}{ Processo } & \multirow{4}{*}{$\begin{array}{l}\text { Ações, reações e } \\
\text { interações no } \\
\text { processo da } \\
\text { mudança } \\
\text { estratégica }\end{array}$} & $\begin{array}{l}\text { Desenvolvimento } \\
\text { da mudança }\end{array}$ & $\begin{array}{l}\text { Aspectos ambientais } \\
\text { Avaliação do ambiente } \\
\text { Característica da } \\
\text { mudança na organização }\end{array}$ & \\
\hline & & & $\begin{array}{l}\text { Reconhecimento } \\
\text { e compreensão } \\
\text { dos problemas }\end{array}$ & $\begin{array}{l}\text { Mudança estratégica } \\
\text { O que buscou mudar } \\
\text { estrategicamente } \\
\text { Formulação da estratégia }\end{array}$ & \\
\hline & & & $\begin{array}{l}\text { Planejamento e } \\
\text { execução da } \\
\text { mudança }\end{array}$ & $\begin{array}{l}\text { Implantação da mudança } \\
\text { estratégica } \\
\text { Liderança na mudança } \\
\text { Problemas encontrados } \\
\text { Ligação entre estratégica } \\
\text { e operacional }\end{array}$ & \\
\hline & & & $\begin{array}{l}\text { Estabilidade da } \\
\text { mudança }\end{array}$ & $\begin{array}{l}\text { Continuidade da } \\
\text { mudança } \\
\text { Aprendizado } \\
\text { Resultado da mudança }\end{array}$ & \\
\hline
\end{tabular}

Fonte: Elaborado pela autora.

Por fim, com o propósito de explorar o material, após a leitura das entrevistas, foram distribuídos os trechos de cada entrevista pelas categorias, para, em seguida, buscar os núcleos de sentido e classificá-los em temáticas mais amplas, em torno das quais foi possivel agrupar os diferentes trechos das entrevistas, de forma a não mais haver entrevistas individuais, mas o conjunto de categorias empíricas.

\section{CONTEXTO, O CONTEÚDO E O PROCESSO DA MUDANÇA ESTRATÉGICA NO SISTEMA FIEC}

Os resultados detalham a identificação do contexto, a descrição do conteúdo e a análise do processo da mudança, que de antemão, consolida-se no Quadro 3, a partir das temáticas evidenciadas na pesquisa. 


\section{Quadro 3: Contexto, conteúdo e processo da mudança estratégica no Sistema FIEC, no período 2009 - 2014, sob a abordagem de Pettigrew (2013)}

\begin{tabular}{|c|c|c|c|c|c|}
\hline & 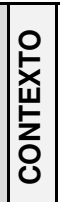 & \multicolumn{2}{|c|}{$\begin{array}{l}\text { Macroambiente: } \\
\text { - Melhoria de indicadores sociais } \\
\text { - Baixa taxa de crescimento da economia } \\
\text { - Baixo nível de investimento }\end{array}$} & $\begin{array}{l}\text { Ambiente setorial: } \\
\text { - Baixos níveis de } \\
\text { investimento, produtividade e } \\
\text { inovação }\end{array}$ & $\begin{array}{l}\text { Ambiente interno: } \\
\text { - Elaboração do PEI do Sistema } \\
\text { Indústria e do Sistema FIEC } \\
\text { - Reformulação Estatuto e } \\
\text { Regimento Eleitoral da FIEC }\end{array}$ \\
\hline & O. & \multicolumn{4}{|c|}{$\begin{array}{c}\text { Projetos de mudança estratégica: } \\
\text { - Mapeamento e redesenho processo e estrutura } \\
\text { - Implantação de solução ERP } \\
\text { - Implantação marketing corporativo } \\
\text { - Modelo de apuração de custos e resultados }\end{array}$} \\
\hline & & \multicolumn{4}{|c|}{ Ações, reações e interações no processo da mudança estratégica: } \\
\hline & \multirow{5}{*}{ 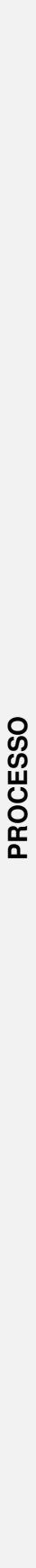 } & 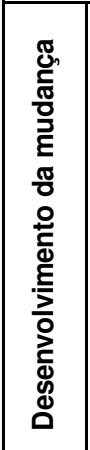 & $\begin{array}{l}\text { Aspectos ambientais: } \\
\text { - Perda de participação da indústria na } \\
\text { economia } \\
\text { - Baixos níveis produtividade/inovação } \\
\text { - Nova forma de relacionamento com o } \\
\text { mercado } \\
\text { - Falta de profissionais qualificados } \\
\text { - Corrupção no cenário político e falta de } \\
\text { políticas de desenvolvimento industrial } \\
\text { - Imagem e cultura do SF de repartição } \\
\text { pública } \\
\text { - Ameaça do fim do repasse p/SF }\end{array}$ & $\begin{array}{l}\text { Avaliação do ambiente: } \\
\text { - Cooperação e influência da } \\
\text { CNI } \\
\text { - Construção de uma teia de } \\
\text { relacionamento } \\
\text { - Alinhamento e engajamento } \\
\text { das lideranças } \\
\text { - Internamente não havia } \\
\text { cultura de análise }\end{array}$ & $\begin{array}{l}\text { Característica da mudança na } \\
\text { organização: } \\
\text { - Ações reativas, buscando ser } \\
\text { proativas } \\
\text { - Estável pela capilaridade } \\
\text { - Busca reinventar-se pela } \\
\text { dinâmica ambiental }\end{array}$ \\
\hline & & 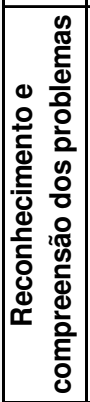 & $\begin{array}{l}\text { Mudança estratégica: } \\
\text { - Ruptura com a cultura passiva do } \\
\text { passado } \\
\text { - Inteligência organizacional } \\
\text { - Integração das casas e olhar sistêmico } \\
\text { - Protagonismo e exemplo das } \\
\text { lideranças }\end{array}$ & \begin{tabular}{l|} 
Formulação da estratégia: \\
- Orientação nacional da CNI \\
- Pensamento crítico e \\
estratégico da presidência, \\
executivos \\
- Mapa estratégico como base \\
- Não envolveu o nível \\
operacional como deveria
\end{tabular} & $\begin{array}{l}\text { O que buscou mudar } \\
\text { estrategicamente: } \\
\text { - Dinâmica de atuação } \\
\text { percebida como essencial } \\
\text { - Sua própria essência, } \\
\text { protagonismo instaurado, } \\
\text { efervescência permanente } \\
\text { - Visão de negócio, sustentável, } \\
\text { eficiente e eficaz }\end{array}$ \\
\hline & & \multirow{2}{*}{ 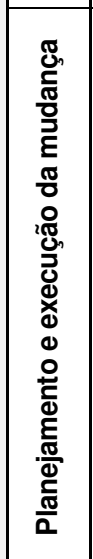 } & \multirow{2}{*}{$\begin{array}{l}\text { Implantação da mudança estratégica: } \\
\text { - Planejamento formal, fases de } \\
\text { implantação } \\
\text { - Atuação da CNI e de consultorias } \\
\text { - Passou por adaptações, sem perder o } \\
\text { foco } \\
\text { - Cronograma de implantação, não de } \\
\text { resultados } \\
\text { - Ocorreu simultaneamente às } \\
\text { atividades } \\
\text { - Comunicação sem um projeto especial } \\
\text { - Centralização treinamento, exercício } \\
\text { lideranças }\end{array}$} & $\begin{array}{l}\text { Liderança na mudança: } \\
\text { - Revisão pessoal para poder } \\
\text { influenciar e reformular } \\
\text { conceitos } \\
\text { - Permeou a ideia da mudança } \\
\text { - Arrastou o esforço dos } \\
\text { colaboradores }\end{array}$ & \multirow{2}{*}{$\begin{array}{l}\text { Ligação entre estratégica e } \\
\text { operacional: } \\
\text { - Otimizou e modenizou } \\
\text { processos para atender novo } \\
\text { contexto } \\
\text { - Padronizou processos para } \\
\text { atuação sistêmica } \\
\text { - Reduziu o isolacionismo das } \\
\text { organizações } \\
\text { - Buscou pensar e atuar como } \\
\text { Sistema para aumentar } \\
\text { amplitude de oferta de soluções }\end{array}$} \\
\hline & & & & $\begin{array}{l}\text { Problemas encontrados: } \\
\text { - Resistência dos } \\
\text { colaboradores e limite } \\
\text { orçamentário } \\
\text { - Complexidade dos } \\
\text { processos e pouca } \\
\text { participação dos } \\
\text { colaboradores nas definições }\end{array}$ & \\
\hline & & 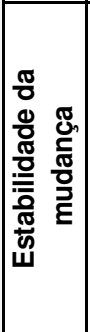 & $\begin{array}{l}\text { Continuidade da mudança: } \\
\text { - Plano crescimento e valorização } \\
\text { colaboradores } \\
\text { - Consolidação e maturação processo } \\
\text { corporativo } \\
\text { - Atenção às mudanças para não perder } \\
\text { o rumo } \\
\text { - Boas parcerias e assessorias }\end{array}$ & $\begin{array}{l}\text { Aprendizado: } \\
\text { - Ganho de parte a parte } \\
\text { - Exercício de mudança de } \\
\text { decisão } \\
\text { - Novo relacionamento com o } \\
\text { risco }\end{array}$ & $\begin{array}{l}\text { Resultado da mudança: } \\
\text { - Foco em resultados e papel } \\
\text { bem definido } \\
\text { - Capacidade de pensar atual e } \\
\text { institucional } \\
\text { - Despertou para uma nova } \\
\text { realidade } \\
\text { - Maturidade do grupo e } \\
\text { organização sólida }\end{array}$ \\
\hline
\end{tabular}

Fonte: Elaborado pela autora com base na pesquisa, adaptado de Gohr (2011). 


\subsection{0 contexto da mudança estratégica no Sistema FIEC}

Segundo Squeff (2015), a partir dos anos 2000, embora tenha sido verificada uma estabilidade nas políticas macroeconômicas, observou-se a emergência de novos desafios, entre os quais se destacaram a consolidação da China como potência econômica, a crise financeira internacional deflagrada nos Estados Unidos em 2008, e seu aumento em 2011, e o processo de redução da participação do valor adicionado pela indústria de transformação no Produto Interno Bruto (PIB).

Cardoso Jr. (2010) considera que a implementação das medidas macroeconômicas não conseguiu imprimir ao país um ritmo adequado de crescimento, apresentando, no período de 2004 a 2009, uma taxa média de crescimento econômico de $4,0 \%$ ao ano, baixa para um país que aspira atingir a condição de nação desenvolvida. Em adição, no tocante ao panorama do PIB brasileiro, Squeff (2015) afirma que, apesar do aumento na taxa média de crescimento do PIB de 1,6\% ao ano, nos anos 1990, para 3,3\% ao ano, entre 2000 e 2009, e para $3,4 \%$ ao ano, entre 2010 e 2013, ainda é muito reduzida frente ao hiato de renda que separa o Brasil dos países desenvolvidos, bem como para diminuir a elevada desigualdade de renda que caracteriza a sociedade brasileira. Ademais, no ano 2014, segundo dados do IBGE, o PIB brasileiro variou 0,1\%, em relação a 2013, apresentando os setores da agropecuária e de serviços uma expansão de $0,4 \%$ e $0,7 \%$, respectivamente, enquanto que o setor industrial recuou $-1,2 \%$.

Contudo, para De Negri e Cavalcante (2014), nos primeiros anos da década de 2000, a economia brasileira passou por um processo de retomada do crescimento do PIB, com redução da pobreza e da desigualdade, tratando-se de uma combinação inédita na história econômica do país, tradicionalmente marcada pela dicotomia entre crescimento versus distribuição da riqueza nacional. A exemplo do índice de Gini, indicadores sociais apresentaram melhoras significativas no período, caindo de cerca de 0,59 , no início da década, para 0,53 , em 2012, tratando-se de uma redução superior a 10\% em dez anos, de um indicador que, nos vinte anos anteriores, havia caído apenas $4 \%$.

No tocante ao nível de investimento, conforme De Neri e Cavalcante (2014), no período de 2000 a 2012, não se observou uma expansão significativa da taxa de investimento, que passou de um nível próximo a $17 \%$ do PIB, no início da década de 2000, para $18 \%$, em 2012. No que diz respeito aos investimentos em tecnologia, enquanto os países ampliaram de forma significativa seus investimentos em P\&D, o Brasil manteve baixos níveis em relação ao PIB, quando a relação P\&D empresarial/PIB, no período entre 2005 e 2008, passou de $0,49 \%$ para $0,53 \%$ do PIB.

No esteio dessa discussão, Bonelli (2014) defende que uma das principais preocupações na agenda contemporânea da economia brasileira é a perda de dinamismo depois da crise global de 2008, associada à redução dos ganhos de produtividade. Depois da elevada taxa de crescimento do PIB registrada em 2010, o fraco desempenho registrado nos anos 2011 a 2013, que se prolonga até 2014, tornou essa preocupação ainda mais aguda.

No tocante ao ambiente setorial do Sistema FIEC, o setor industrial, para Laplane (2015), as tentativas de reorganizar e expandir a atividade industrial no país enfrentaram várias dificuldades, como, em 2011, a retração do comércio internacional e dos mercados importadores de manufaturas brasileiras. Em adição, a partir de 2012, os investimentos perderam fôlego e os aumentos da produtividade foram insuficientes para enfrentar a concorrência externa em condições de apreciação cambial e de aumento do salário real.

Mais especificamente, o setor industrial do Ceará, diretamente relacionado ao raio de atuação do Sistema FIEC, percebeu-se o peso que a indústria possui na estrutura da economia estadual, representando, no período de 2002 a 2011, uma média de $23,38 \%$ de participação no valor adicionado total da economia cearense (BEZERRA DE MENEZES et al., 2014). No período de 2008 a 2012, constatou-se que a economia industrial do Ceará cresceu em um ritmo superior à economia nacional, com exceção do ano de 2011. Nesse período, enquanto o comportamento da taxa de crescimento do PIB Industrial do Brasil apresentou um recuo de 4,2\%, em 2008, para negativos -0,8\%, em 2012, a taxa de crescimento do PIB Industrial do Ceará passou de 5,9\% em 2008 para 2,6\% em 2012 (SENAl, 2014). Entre 2001 e 2011, a produtividade do trabalhador industrial cearense registrou uma redução de $14,3 \%$. Este percentual foi superior à queda observada para indústria nacional, que foi de $13,5 \%$ no período. Como resultado, a produtividade do operário industrial cearense apresenta uma expressiva defasagem em relação à produtividade nacional.

Para Cavalcante e Magalhães (2014), 0 ano de 2011 foi um período com menor dinamismo na atividade industrial no Ceará. Afetada pelos desdobramentos da crise internacional e por problemas de competitividade, a 
indústria cearense experimentou reduções na produção que acabaram por diminuir sua participação no valor adicionado da economia. Já nos anos de 2012 e 2013, a indústria cearense, influenciada pela indústria da construção civil, apresentou uma taxa de crescimento de 2,6\% e 5,62\%, respectivamente. Tal cenário acabou por suceder, em 2014, um recuo de 1,87\% no comportamento da taxa de crescimento da indústria cearense, o que refletiu, ainda, um saldo negativo de empregos gerados e da produção física nesse ano, repetindo os sinais de esgotamento de crescimento do cenário nacional (IPECE, 2014).

Juntamente a esse contexto externo, a presente pesquisa observou o contexto interno do Sistema FIEC, que, segundo Pettigrew (2013) é composto pelos fatores que influenciam a formação das estratégias dentro da organização. Observou-se, então, dois marcos no período estudado: a atualização do Estatuto e do Regulamento Eleitoral da FIEC e a elaboração do planejamento estratégico integrado, que, segundo o entrevistado 5 , constituem-se como "as duas matrizes essenciais ao entendimento do Sistema FIEC". Pode-se entender tal afirmação, a partir do relato do entrevistado 1:

\begin{abstract}
Quem elegia a Diretoria da FIEC eram os delegados dos sindicatos. Aquele sistema de eleição por delegado não era justo, e aí começou-se a fazer um trabalho de preparação de um novo Estatuto, fazendo com que a eleição fosse com o voto direto dos associados dos sindicatos. 0 empresário era quem ia escolher a diretoria da FIEC, dentro do sindicato. Conseguimos fazer essa mudança, que foi uma coisa que deu uma abertura muito grande e uma credibilidade maior na nossa instituição. Eu queria passar a temporada para tentar reunificar a instituição (ENTREVISTADO 1).
\end{abstract}

Foi nesse contexto de reunificação que se iniciou a discussão acerca do planejamento estratégico integrado, considerado pelos gestores entrevistados como o principal norteador do redirecionamento das ações estratégicas. A partir dessa discussão, foram elaborados os mapas estratégicos da indústria em dois momentos distintos: para o período de 2007 - 2015 e, posteriormente, 2013 - 2022. Tais iniciativas tiveram como ponto de partida as orientações da $\mathrm{CNI}$, que tendo em vista os cenários e os desafios da indústria nacional, iniciou uma reflexão conjunta sobre o futuro da indústria.

Uma das principais contribuições do mapa estratégico (2007-2015) foi a criação de um sistema de gestão para o acompanhamento da sua implementação, fixando-se como objetivo central a competitividade com sustentabilidade, tendo, ainda, como principais determinantes a produtividade e a inovação (CNI, 2013). Nesse sentido, alinhado aos referidos mapas estratégicos da indústria, o Sistema FIEC tomou para si a agenda estratégica nacional, elaborando seu planejamento estratégico integrado para o período de 2008 - 2014, visando à consolidação do modelo de gestão corporativo.

Foi diante desse contexto que o Sistema FIEC buscou implantar, especificamente no período de 2009 a 2014, projetos de mudança estratégica, que a seção a seguir apresenta como conteúdo da mudança.

\title{
4.2 0 conteúdo da mudança estratégica no Sistema FIEC
}

Diante do contexto destacado, o Sistema FIEC deu início ao desenvolvimento de ações de mudança estratégica, que o presente estudo tomou como o conteúdo da mudança. Ademais, o presente trabalho entende que as mudanças organizacionais no Sistema FIEC estão em consonância com Motta (2007). Esse autor defende que o modelo da intenção estratégica considera que a organização pode adaptar-se ao seu ambiente através de reestruturação planejada, essencialmente direcionada pela alta gerência. Corrobora com tal entendimento o relato do entrevistado 1, no qual afirmou:

A gente queria fazer uma coisa que fosse a cara do Sistema FIEC. Tinha um organograma na parede da presidência que o que se via acontecer era totalmente diferente. Eu disse que nós tínhamos que fazer um projeto para reestruturação organizacional. Começamos a fazer um trabalho com uma consultoria, longo e difícil. Iniciamos alguns projetos estratégicos estruturantes, porque a diretoria que formamos foi uma diretoria de peso, qualificada, de gente comprometida. Tivemos uma diretoria muito atuante e efetiva, falávamos olhando pra frente, olhando para o futuro (ENTREVISTADO 1).

Por meio de análise documental, realizada em planos, projetos e relatórios de gestão existentes na organização, foi possível constatar que o planejamento estratégico do Sistema FIEC, iniciado em 2008, e alinhado

Revista Alcance - Eletrônica - vol. 23 - n. 3 - jul./set. 2016 
ao planejamento estratégico do Sistema Indústria, foi o pontapé inicial para a mudança estratégica, que pode ser figurada por meio dos projetos: 1) mapeamento e redesenho de processos e estrutura organizacional; 2) implantação de solução integrada de gestão empresarial; 3) desenvolvimento e implantação da função marketing corporativo; 4) implantação do modelo de apuração e comunicação de custos e resultados.

Descrevendo os referidos projetos, tem-se que o Projeto de Mapeamento e Redesenho de Processos e Estrutura Organizacional teve início em 2011, quando o Sistema FIEC buscou modernizar seus métodos e fluxos, com foco na melhoria das suas áreas corporativas. Assim, o objetivo do projeto consistiu em melhorar os processos existentes, atuando em consonância com as diretrizes estratégicas da organização, no sentido de favorecer 0 alinhamento sistêmico entre FIEC, SESI, SENAI e IEL e de promover a racionalização e a otimização organizacional.

No ano de 2012, iniciou-se o trabalho de planejamento do Projeto de Implantação da Solução Integrada de Gestão Empresarial no Sistema FIEC. O trabalho se deu se forma conjunta entre a CNI e o Sistema FIEC, consistindo numa iniciativa da própria $\mathrm{CNI}$ de formar uma base tecnológica que unificasse toda a rede de entidades do Sistema Indústria. Assim, a solução sistêmica partiu para o ERP. A iniciativa refletia a nova postura estratégica da organização, buscando um novo modelo de governança que proporcionasse alto desempenho e competitividade.

Verificou-se, ainda, que em 2009 o Sistema FIEC iniciou o Projeto de Desenvolvimento e Implantação da Função Marketing. Com o objetivo geral de implantar a área de marketing corporativo, o projeto visou desenvolver e gerir estratégias orientadas para o relacionamento do Sistema FIEC com seus diversos públicos, promovendo análises e pesquisas de mercado e metodologias para, em conjunto com as entidades, desenvolver seu portfólio de produtos e serviços.

Por fim, em 2011, o Sistema FIEC iniciou a implantação do Projeto Modelo de Apuração e Comunicação de Custos e Resultados. Tal projeto visou assegurar a clareza na divulgação de objetivos, medição e comunicação de resultados, por meio de um modelo nacional e de um sistema de informação único, padronizado, para apuração e comunicação de custos e resultados.

Assim, após identificar o contexto e descrever o conteúdo da mudança, na próxima seção, o presente trabalho apresenta como ocorreu o processo da mudança, a partir dos relatos dos gestores entrevistados da organização.

\subsection{0 processo da mudança estratégica no Sistema FIEC}

Nesta seção descreve-se o processo de mudança estratégica a partir da compreensão dos gestores, evidenciados a partir das entrevistas realizadas e tratadas por meio da análise de conteúdo. Tomou-se como norte os estágios da mudança estratégica: desenvolvimento da mudança, reconhecimento e compreensão dos problemas, planejamento e execução, e estabilidade da mudança.

Para o estudo do primeiro estágio, desenvolvimento da mudança, buscou-se evidenciar junto aos gestores da organização questões inerentes aos aspectos ambientais, à avaliação do ambiente e à característica da mudança na organização. Dessa forma, quando questionados a respeito dos aspectos ambientais que vieram influenciar tanto o setor de atuação do Sistema FIEC quanto o seu próprio contexto interno, os gestores relataram leituras de um ambiente em mutação, retratando ora importantes avanços, ora problemas graves, principalmente no que diz respeito ao setor produtivo industrial.

O principal problema de influência do ambiente apontado pelos gestores foi a própria dinâmica da economia nacional. Conforme afirmaram os entrevistados 7 e 9 , a indústria tem perdido participação na economia ano a ano. Apesar do enorme potencial de ampliação da geração de riqueza, o setor de serviços é quem tem tomado essa dianteira. No estado do Ceará, "apesar do setor industrial ter crescido mais que a média nacional, esse crescimento não é expressivo para que a gente tenha uma tranquilidade em momento forte de demanda de trabalho" (ENTREVISADO 9).

Outro ponto do contexto ambiental mencionado pelos gestores foi a questão da baixa produtividade industrial, relacionada, ainda, a fatores como os baixos níveis de inovação. Segundo o entrevistado 4, "o Sistema FIEC verificou que a produtividade brasileira não crescia, e que, portanto, precisava atuar de forma a ajudar as empresas industriais a terem um aumento de produtividade". 
Percebeu-se, então, pelos relatos dos gestores, que o ambiente exigia que o Sistema FIEC acompanhasse as novas formas de atuação e de relacionamento com o mercado. Essa reflexão levou a organização a orientar suas ações sob a ótica do mercado, a interpretar as mudanças no ambiente externo e alinhar seu ambiente interno.

Em diversos relatos, verificou-se a frequência de uma temática recorrente, que envolveu a questão da redução, ou mesmo do fim do repasse dos recursos compulsórios ao Sistema FIEC. De acordo com o entrevistado 8:

\begin{abstract}
A questão de possibilidade de revisão do compulsório levantou a visão do Sistema Indústria no sentido de elevação da sua eficiência. Até pouco tempo, se trabalhava muito a relevância do Sistema Indústria e não a questão da eficiência. Assim, essa questão da possível revisão do compulsório redirecionou as estratégias do Sistema FIEC no sentido de elevar a sua eficiência, em se preocupar com sua sustentabilidade financeira, que até pouco tempo não era uma preocupação real (ENTREVISTADO 8).
\end{abstract}

Os gestores expressaram, ainda, preocupações com o cenário político, remetendo, principalmente, às temáticas corrupção na política e falta de políticas de desenvolvimento industrial. Nesse contexto, observou-se nos depoimentos a insatisfação dos gestores com a imagem do Sistema FIEC associada a uma repartição pública, que acabava permeando na cultura na organização uma gestão sem medição de resultados e de acomodação dos colaboradores, incompatível com a produtividade demandada. Tal preocupação acabou despertando nos gestores a necessidade de maior controle e maior transparência da aplicação dos recursos, que passava também pela mudança da própria cultura da organização.

Nesse sentido, observou-se que a mudança na cultura e no comportamento da organização se fazia imperativo para a mudança estratégica que o Sistema FIEC almejava para fazer frente ao contexto percebido. Percebe-se aqui uma concordância com as ideias de Ansoff (1990), apresentadas na seção 2 deste trabalho.

No tocante ao processo que levou à avaliação do ambiente, os gestores afirmaram que o Sistema FIEC contou com a cooperação e a influência da CNI, que "iniciou um processo interno de análise de cenários e isso contagiou as demais Federações, e se deu através da elaboração de estudos e pesquisas, de reuniões e discussões" (ENTREVISTADO 9). Ressaltaram ainda que a presidência e a diretoria do Sistema FIEC procuraram construir uma teia de relacionamento para o desenvolvimento para discussões, buscando envolver e ouvir as lideranças dos sindicatos, empresas e clientes. Distintamente, os entrevistados 5 e 8 apresentaram a percepção de um Sistema FIEC que, internamente, não tinha uma cultura de trabalho de análise mais específica do ambiente, desempenhando um papel muito mais político institucional, de defesa dos interesses econômicos da indústria e dos seus afiliados, do que, propriamente, uma visão estratégica do ambiente em que estava vivendo.

No tocante à característica da mudança na organização, quando os gestores foram questionados se as decisões estratégicas, no período estudado, foram reativas ou proativas ao contexto percebido, foi observado uma mescla de percepções, que ora descrevia as mudanças como ações reativas, ora um pouco de cada componente. Foi, ainda, ressaltada a questão cultural da organização, que vem mudando com a evolução dos tempos, em consonância com o já ressaltado Wood Jr. et al. (1994) na seção 2.

Partindo para o segundo estágio da mudança, reconhecimento e compreensão dos problemas, o presente estudo traz questões que envolveram as ações de mudança estratégica, procurando evidenciar o que a organização buscou mudar estrategicamente e o processo de formulação da estratégia.

Em conformidade com Mintzberg et al. (2007), que caracterizam a mudança estratégica como um processo organizacional, inseparável da estrutura, do comportamento e da cultura, de uma forma geral, ao descreverem as ações percebidas como mudanças estratégicas, os gestores as fizeram ressaltando, juntamente aos objetivos de melhorar a eficiência da organização, a intenção de despertar os colaboradores para a necessidade de uma postura mais ativa diante dos desafios dos novos tempos.

Conforme os relatos, as mudanças tiveram como foco a tratativa do Sistema FIEC como negócio, ou ainda, que a dinâmica da mudança foi juntar esforços, sendo citadas as ações de implantação da área de marketing, nas quais se buscou um novo modelo de negócio, de relacionamento como o mercado; de implantação de uma nova estrutura corporativa e de processos, de forma a possibilitar a integração do planejamento estratégico 
da organização, otimizar recursos, garantir a unicidade de visão e de comunicação de resultados; de mudança do sistema de informação, para uma gestão mais eficiente.

Os entrevistados relataram, de uma forma geral, que as mudanças estratégicas tiveram a preocupação de construir na organização um olhar sistêmico, de considerar o esforço coletivo. Assim, essas ações, que, a princípio, tomaram a forma de projetos implantados em momentos distintos, constituíam uma única orientação estratégica, que tinha a expectativa de trazer para o Sistema FIEC assertividade, agilidade, planejamento e controle.

É importante resgatar que, na análise documental, este estudo evidenciou quatro grandes projetos de mudança na organização, contudo, alguns gestores apontaram, ainda, as reformulações do Estatuto e do Regulamento Eleitoral da FIEC em paralelo a essas ações de mudanças, como marcos nesse processo, que buscaram, além de iniciar um processo de reunificação do Sistema FIEC, chamar as lideranças para o protagonismo das mudanças. Articulando essa discussão, os entrevistados afirmaram, de uma forma geral, que o Sistema FIEC buscou mudar estrategicamente a sua dinâmica de atuação, mudar a sua essência e fazer perceberse como essencial no seu contexto.

Buscou mudar também a sua própria visão de negócio, que, segundo o entrevistado 2, constituiu-se numa atuação decisiva e fundamental para a sustentabilidade do Sistema FIEC, para dar uma nova roupagem, uma nova visão de como se trabalhar o negócio, a fim de fazer face ao momento atual, que pede, e pedia naquela época, que o negócio fosse mais produtivo e mais rentável, principalmente em função de mudanças conjunturais.

No tocante ao processo de formulação das estratégias no Sistema FIEC, os entrevistados relataram, de uma forma geral, que, assim como aconteceu na fase de avaliação do ambiente, a CNI participou orientando e cooperando a formulação das estratégias, tomando-se como referência, uma visão nacional. Os entrevistados ressaltaram, ainda, que a formulação tomou como base o trabalho de atualização do mapa estratégico da organização, com novos objetivos, novas metas e indicadores estratégicos. Em concordância, Bethlem (2002), apresentado na seção 2, coloca os objetivos organizacionais com ponto de partida para a determinação da estratégia.

Ao trazer a questão do compartilhamento dos problemas e do próprio processo de formulação com os colaboradores, embora alguns entrevistados tenham ressaltado a importância do compartilhamento do processo e que se buscou, de fato, envolver todos os colaboradores, outros entrevistados não perceberam o processo da mesma forma, expressando uma fase da mudança que não envolveu o nível operacional da organização como deveria.

Para o estudo do estágio planejamento e execução da mudança, este estudo buscou reunir questões acerca da implantação da mudança, dos problemas encontrados, da liderança na mudança e da ligação entre a estratégia e o operacional.

Nessa perspectiva, os gestores relataram que a implantação foi previamente formalizada, medida e acompanhada, seguindo um planejamento formal. Foram promovidas fases de implantação, contando tanto com a atuação da $\mathrm{CNI}$ quanto com o suporte de consultorias locais contratadas. As mudanças foram contratadas segundo um cronograma e a decisão, a cada momento, por parte da presidência, diretoria e os altos níveis da administração.

Segundo os entrevistados, de uma forma geral, verificou-se que a comunicação e a preparação dos colaboradores foram pontos críticos nessa fase, apresentando dificuldades ou até certa negligência no momento. Segundo 0 entrevistado 4, "as metas e os resultados das mudanças foram comunicados em todas as instâncias, através de reuniões, do site e de comunicados internos, contudo, não se teve um projeto especial de comunicação".

Em meio a essas perspectivas, as lideranças na mudança, de acordo com o entrevistado 9, "tiveram que passar por uma revisão pessoal para poder influenciar positivamente as pessoas dentro desse processo de mudança". Então, depois dessa revisão pessoal, os líderes fizeram o papel de permear nas organizações a ideia de chegar e mudar". Enfim, segundo o entrevistado 4, "o presidente da FIEC teve um papel estratégico, pois disse o rumo que ele quis, a visão era dele" (ENTREVISTADO 4).

A respeito dos problemas encontrados na implantação das mudanças estratégicas, em conformidade com Mintzberg, Ahlstrand e Lampel (2007), já ressaltados na seção 2, os entrevistados relataram, além da falta de comunicação como ponto crítico, a resistência dos colaboradores como problema, sendo esse o mais citado entre 
os entrevistados. Para o entrevistado 10, "a resistência, por conta de aspectos culturais, em sair dos seus padrões de comportamento, foi o principal problema". Foram mencionados, ainda, o limite orçamentário, a complexidade dos processos e o baixo nível de participação dos colaboradores na definição de procedimentos, processos e estratégia.

Já no tocante à ligação entre estratégica e operacional, segundo Hickson e Puch (2004), o elo entre a mudança estratégica e operacional remete ao entendimento de que os processos de mudança em níveis estratégicos e operacionais tanto têm que ocorrer simultaneamente, quanto devem se tornar processos políticos, uma vez que tais processos, ao pressionarem por mudança, encontram oposição. Em consonância com este entendimento, conforme os relatos, o processo de mudança estratégica no Sistema FIEC objetivou preparar a organização com as melhores condições operacionais e gerenciais para o novo contexto de atendimento à indústria e aos novos tempos do cenário nacional e mundial.

Os entrevistados expressaram, ainda, o entendimento de que a modernização e a otimização dos processos operacionais objetivavam uma padronização que acabasse levando os colaboradores, em todos os níveis organizacionais, a pensarem as organizações - SESI, SENAI, IEL e FIEC, como sistema e, então, atuassem de forma sintonizada e fortalecida. Assim, os processos operacionais buscavam importantes resultados, traçados pelas novas estratégias. E segundo o entrevistado 3,

Procurou reduzir o isolacionismo das entidades, que, agindo isoladas, perdiam oportunidade de serem mais efetivas no atendimento às empresas, na medida em que cada entidade poderia compor, juntas, um pacote a ser ofertado com uma maior amplitude de soluções (ENTREVISTADO 3).

Por fim, para o estudo da estabilidade da mudança, buscou-se evidenciar aspectos sobre a continuidade da mudança, o aprendizado e o resultado da mudança. Sobre a continuidade de mudança, o presente estudo destaca que essa discussão foi marcada pelo fim do mandato de presidência e diretoria, que iniciou as mudanças, e pela eleição e posse de uma nova presidência e diretoria. Esse momento foi retratado pelo entrevistado 1 da seguinte forma, "o objetivo era passar a marola e continuar a braçada, fazer com que, aqueles que fazem parte do colegiado responsável pelo desempenho de todos, ficassem juntos".

Afirmou, ainda, o entrevistado 4 que a organização "tinha um plano de pessoal, de valorização, que foi feito, discutido, analisado e apresentado à direção, que dava condições das pessoas terem amor por lá. A ideia era formar gente através de um plano de crescimento". Ademais, segundo o entrevistado 9 ,

O Sistema FIEC tem hoje um roteiro apontando a direção, que ainda está em construção. Apesar da comunicação, precisar melhorar. Já foi dito o que precisa mudar, o que vai passar, o que passa a ser e o que não vai mais ser. É preciso consolidar as mudanças que realmente precisam acontecer, para que princípios, cultura, procedimentos, sejam consolidados de forma corporativa, sem retroceder (ENTREVISTADO 9).

Contudo, para o entrevistado 10, "é muito difícil pensar a continuidade das mudanças nesse sistema de eleições que o Sistema FIEC possui, presidencialista. Há algumas coisas que são continuadas e outras interrompidas".

No tocante ao aprendizado no processo de mudança, foi relatado pelos entrevistados como um ganho de parte a parte ou como uma escola. De uma forma geral, os entrevistados afirmaram que as experiências vividas enriqueceram todo o processo, no qual se pode aprender com as respostas que as pessoas deram, com as mudanças de atitude e com os engajamentos. 0 aprendizado se deu ainda por meio do exercício de mudança de decisão ou de conduta, quando se precisou maior efetividade, trazendo ganho de aprendizado para quem planejou, executou e para quem participou operacionalmente. Segundo o entrevistado 3,

$\mathrm{O}$ aprendizado que se tirou foi com o erro. Aprendeu-se que não se pode ficar repetindo os velhos erros. Então, partimos para erradicá-los e entendemos que tínhamos que definir um novo relacionamento com o risco, porque mudar e inovar é uma atividade de risco, envolvendo pessoas e recursos, e pode não dá certo (ENTREVISTADO 3). 
Por fim, quando questionado a respeito do resultado da mudança, se tais mudanças, afinal, foram para melhor ou para pior, assim relatou o entrevistado 3, "essa mudança estratégica trouxe um descerramento de cortinas. Estamos diante de grandes desafios e somos constantemente avaliados. Então tivemos que implantar mais intensidade, mais avaliação sobre o nosso papel. E isso resultou numa maturidade de grupo".

Finaliza o entrevistado 1: "essa avaliação é a sociedade que faz e o que eu tenho ouvido é que o pessoal em geral se orgulha de ter uma FIEC aqui no Ceará como é a nossa FIEC de hoje. O que está aí é uma organização sólida".

Por fim, entende-se que os resultados evidenciados no presente estudo podem alinhar-se aos estudos de Pettigrew (2013), apresentado na seção 2. 0 citado autor observou que a sequência de mudanças consistiu numa mistura complexa de ajustes no núcleo de crenças dos principais tomadores de decisão, seguida por mudanças na estrutura, que reforçavam as mudanças nas crenças, que, por sua vez, destas mudanças nas crenças e estrutura, emergiram a nova estratégia. Nessa linha de pensamento, a cultura organizacional, considerada no seu nível mais profundo como um conjunto complexo de valores e crenças dos principais tomadores de decisão, configura-se como mecanismo chave para promover as mudanças estratégicas organizacionais.

\section{CONSIDERAÇÕES FINAIS}

O tema desta pesquisa está relacionado ao estudo da mudança estratégica no Sistema FIEC, no período de 2009 a 2014 e, para o seu desenvolvimento, adotou-se a metodologia de análise da mudança estratégica proposta por Pettigrew (2013), focando as três dimensões da mudança: contexto, conteúdo e processo.

Foi identificado um contexto marcado pela baixa taxa de crescimento da economia, além dos baixos níveis de investimento, inovação e produtividade. Constatou-se, ainda, a melhoria de indicadores sociais, como nível de emprego, escolaridade e esperança de vida. No setor industrial, a perda da participação da produção na economia. No Estado do Ceará, apesar de o setor industrial ter apresentado um desempenho econômico superior à média nacional, nos anos iniciais deste estudo, apresentou uma queda na sua trajetória nos anos finais. Observou-se, ainda, o contexto interno do Sistema FIEC caracterizado pelos momentos de elaboração do planejamento estratégico integrado, visando à consolidação do modelo de gestão corporativo. Identificou-se, também, que o ambiente interno foi caracterizado por três mandatos de diretoria. Dois mandatos de um mesmo presidente, que liderou a reformulação do estatuto e do regimento eleitoral da organização, buscando iniciar um processo de reunificação e protagonismo das lideranças; e finalizando o período do estudo, o início do mandato de uma nova diretoria.

No tocante ao processo da mudança, foi possível constatar que o desenvolvimento da mudança estratégica no Sistema FIEC ocorreu a partir da avaliação do ambiente, iniciada pela CNI e compartilhada para as federações das indústrias estaduais. No Ceará, o Sistema FIEC contou com o engajamento das lideranças estratégicas, que percebendo um ambiente que exigia novas formas de atuação, iniciaram um processo de mudança estratégica, buscando se reinventar pela nova dinâmica.

0 reconhecimento e a compreensão dos problemas diante desse ambiente deram condições à implantação de um conjunto de ações, descritas como o conteúdo da mudança, que apesar de iniciarem em períodos distintos, faziam parte de uma estratégia que visava à ruptura de uma cultura de passividade e de isolacionismo, buscando uma inteligência organizacional que passava pela integração da atuação das organizações como Sistema FIEC. Como estratégia, o Sistema FIEC, ao buscar mudar a sua visão de negócio, mudou a sua própria essência, buscando ser percebida como essencial para o desenvolvimento das indústrias.

Assim como no processo de formulação da estratégia, o planejamento e a execução da mudança seguiram a orientação e a cooperação da CNI. A liderança nesse processo passou pela revisão de seus conceitos de atuação para poder permear na organização a ideia da mudança e arrastar o esforço dos colaboradores. Contudo, a implantação das ações, que buscou ligar a estratégia ao operacional por meio de processos que reduzissem 0 isolacionismo das organizações, encontrou, além do limite orçamentário e da complexidade dos novos processos, a resistência dos colaboradores, sinais de uma comunicação e de uma preparação que poderiam ter sido mais descentralizadas, com o maior envolvimento dos colaboradores.

A estabilidade da mudança foi pensada pela liderança por meio de planos de crescimento dos colaboradores, a fim de consolidar e maturar um processo de gestão corporativo atento às mudanças. Como 
aprendizado, a organização adquiriu um novo relacionamento com o risco, ciente que o exercício da mudança, apesar de encontrar problemas, é um processo de ganho de parte a parte, uma escola que despertou a organização para a nova realidade.

Por fim, o presente trabalho considera que a pesquisa desenvolvida sobre a mudança estratégica no Sistema FIEC pode contribuir com o estudo acadêmico no campo da administração e para a compreensão e a gestão da mudança estratégica organizacional, ao identificar e analisar uma variedade de aspectos relacionados à mudança organizacional, buscando explorar a complexidade do fenômeno, dentro do contexto em que ocorreu e vivenciado pelos indivíduos. Somou-se a contribuição ao Sistema FIEC, através da ampliação do conhecimento sobre como ocorreu a mudança estratégica no período estudado, numa visão contextualista, proporcionando à direção da organização a possibilidade de avaliar o comportamento estratégico adotado e de ter subsídios para ações e decisões futuras.

Como sugestão para futuros estudos, que permitam a evolução da temática ou do estudo realizado, recomenda-se a utilização da mesma abordagem, em federações de outros estados, que passaram pela mesma orientação estratégica. Sugere-se, ainda, a realização dessa mesma pesquisa, incluindo outros colaboradores da organização, a fim de proporcionar um novo olhar sobre o mesmo problema, dado que este estudo limitou as entrevistas aos gestores do nível estratégico da organização. E sugere-se, por fim, desenvolver uma pesquisa que aprofunde 0 estudo quanto aos resultados colhidos com a mudança estratégica na organização, contando com um maior período de maturação de todo o processo de implantação.

\section{REFERÊNCIAS}

AMIS, J. et al. Strategic change and the role of interests, power, and organizational capacity. Journal of Sport Management, v. 18, n. 2, p. 158-198, 2004.

ANSOFF, H. I. A nova estratégia empresarial. São Paulo: Atlas, 1990.

BETHLEM, A. Estratégia empresarial: conceitos, processo e administração estratégica. 4. ed. São Paulo: Atlas, 2002.

BEZERRA DE MENESES, A. S.; et al. Indústria. In: BARRETO, F. A. F. D.; BEZERRA DE MENEZES, A. S. Desenvolvimento econômico do Ceará: evidências recentes e reflexões. Fortaleza: IPECE, 2014.

BONELLI, R. Produtividade e armadilha do lento crescimento. In: DE NEGRI, F.; CAVALCANTE, L. R. Produtividade no Brasil: desempenho e determinantes. Brasilia: IPEA, 2014. v. 1. p.111-142.

BORGES, R. S. G. Implementação de mudança organizacional e o papel das práticas de recursos humanos: um estudo de caso brasileiro. Brazilian Business Review, Vitória, v. 6, n. 3, p. 299-311, set./dez.2009.

BRUNNINGE, O.; NORDQVIST, M.; WIKLUND, J. Corporate governance and strategic change in SMEs: The effects of ownership, board composition and top management teams. Small Business Economics, v. 29, n. 3, p. 295-308, 2007.

CARDOSO JR, J. C. Infraestrutura econômica no Brasil: diagnósticos e perspectivas para 2025. Brasília: IPEA, 2010.

CAVALCANTE, A. L.; MAGALHÃES, K. A. Indicadores Econômicos do Ceará 2012. Fortaleza: IPECE, 2014.

COMIN, L. C.; SAUSEN, J. O. Uma análise do processo de mudança e crescimento de uma empresa no setor da construção civil: um olhar a partir da formação de estratégias. Perspectivas Contemporâneas, v. 11, n. 1, p. 120-139, 2016.

CONFEDERAÇÃO NACIONAL DA INDÚSTRIA (CNI). Cenários integrados. Brasilia: CNI, 2013.

CONFEDERAÇÃO NACIONAL DA INDÚSTRIA (CNI). Perfil da indústria nos estados 2014. ed. rev. Brasília: CNI, 2014.

CORAIOLA, D. M.; OLIVEIRA, S. A.; GONÇALVES, S. A. Se a estratégia é prática, quem são seus praticantes? Revista Brasileira de Estratégia, Curitiba, v. 5, n. 3, p. 231-242, set./dez. 2012.

DE NEGRI, F.; CAVALCANTE, L. R. Produtividade no Brasil: desempenho e determinantes. Brasília: Ipea, 2014.

Revista Alcance - Eletrônica - vol. 23 - n. 3 - jul./set. 2016 
FERREIRA, M. C. B.; CAMARGO-BORGES, C. Narrativas estratégicas para a mudança organizacional: a perspectiva da linguagem poética. Nova Perspectiva Sistêmica, v. 25, n. 54, p. 17-28, 2016.

FISS, P. C.; ZAJAC, E. J. The symbolic management of strategic change: Sensegiving via framing and decoupling. Academy of Management Journal, v. 49, n. 6, p. 1173-1193, 2006.

GIOIA, D. A.; CHITTIPEDDI, K. Sensemaking and sensegiving in strategic change initiation. Strategic Management Journal; Sep 1991; 12, 6; ABI/INFORM Global pg. 433.

GOHR, C. F.; SANTOS, L. C. Contexto, conteúdo e processo da mudança estratégica em uma empresa estatal do setor elétrico brasileiro. Revista de Administração Pública, Rio de Janeiro, v. 45, n. 6, p. 1673-1706, nov./dez. 2011.

GRAETZ, F. Strategic change leadership. Management decision, v. 38, n. 8, p. 550-564, 2000.

HICKSON, D. J.; PUGH, D. S. Os teóricos das organizações. Rio de Janeiro: Qualitymark, 2004.

INSTITUTO DE PESQUISA E ESTRATÉGIA ECONÔMICA DO CEARÁ (IPECE). IPECE Conjuntura. Fortaleza: IPECE, 2014.

JOHNSON, G.; SCHOLES, K.; WHITTINGTON, R. Exploring corporate strategy. 8. ed. England: Pearson Education, 2008.

LAPLANE, M. F. A indústria ainda é o motor do crescimento? Teoria e evidências. In: DE TONI, J. Dez anos de política industrial: balanço e perspectivas. Brasília: ABDI, 2015. p. 23-40.

MINAYO, M. C. S.; DESLANDES, S. F.; GOMES, R. Pesquisa social: teoria, método e criatividade. 28. ed. Rio de Janeiro: Vozes, 2009.

MINTZBERG, H.; LAMPEL, J.; QUINN, J. B.; GHOSHAL, S. O processo da estratégia: conceitos, contextos e casos selecionados. 4. ed. Porto Alegre: Bookman, 2007.

MINTZBERG, H.; AHLSTRAND, B.; LAMPEL, J. Transformando organizações. In: MINTZBERG, H.; LAMPEL, J.; QUINN, J. B.; GHOSHAL, S. O processo da estratégia: conceitos, contextos e casos selecionados. 4. ed. Porto Alegre: Bookman, 2007. p. 152-159.

MOTTA, P. R. Transformação organizacional: a teoria e a pratica de inovar. Rio de Janeiro: Qualitymark, 2007.

PALÁCIOS, F. A. C. Mudança estratégica em uma universidade pública: interferência da interpretação dos gestores no processo. Amazônia, Organizações e Sustentabilidade, v. 3, n. 2, p. 83-99, 2014.

PETTIGREW, A. M. A cultura das organizações é administrável? In: FLEURY, M. T. L.; FISCHER, R. M. (Org.). Cultura e poder nas organizações. 2. ed. 17. reimp. São Paulo: Atlas, 2013. p. 145-153.

PETTIGREW, Andrew M. Longitudinal field research on change: Theory and practice. Organization science, $v$. 1, n. 3, p. 267-292, 1990.

PETTIGREW, A.M. Context and action in the transformation of the firm. Journal of Management Studies, v. 24, n. 6, p. 649-670, nov. 1987.

PETTIGREW, A. M. Strategy formulation as a political process. International Studies of Management \& Organization, p. 78-87, 1977.

PORTER, M. E. Estratégia competitiva: técnicas para análise de indústria e da concorrência. 2. ed. Rio de Janeiro: Elsevier, 2004.

RICHARDSON, R. J. et al. Pesquisa social: métodos e técnicas. 3. ed. São Paulo: Atlas, 2008.

ROBBINS, Stephen P. Comportamento organizacional. 11. ed. São Paulo, SP: Prentice Hall, 2005.

SAEED, B.B; WANG, W. The art of organizational diagnosis: pathogens and remedies. iBusiness, v. 5, n. 2 , p.55-58, 2013.

SERVICO NACIONAL DE APRENDIZAGEM INDUSTRIAL (SENAI). Indústria cearense: perfil, perspectivas, desafios e propostas para o desenvolvimento industrial do estado. Fortaleza: SENAI, 2014. 
SILVA, J. R. G.; VERGARA, S. C. Sentimentos, subjetividade e supostas resistências à mudança organizacional. Revista de Administração de empresas, São Paulo, v.43, n. 3, p. 10-21, jul./set. 2003.

SQUEFF, G. C. Dinâmica macrossetorial brasileira. Brasília: Ipea, 2015.

SUAREZ, F. F.; OLIVA, R. Environmental change and organizational transformation. Industrial and Corporate Change, v. 14, n. 6, p. 1017-1041, 2005.

WOOD JR, T.; CURADO, I. B.; CAMPOS, H. M. Vencendo a crise: mudança organizacional na Rhodia Farma. Revista de Administração de Empresas, v. 34, n. 5, p. 62-79, 1994.

YIN, R. K. Estudo de caso: planejamento e métodos. 5. ed. Porto Alegre: Bookman, 2010. 